\title{
Efficient Market Hypothesis in Emerging Market - a Conceptual Analysis
}

\author{
Hamza Zubairu Kofarbai, M.Phil, PhD in - view \\ Al-Qalam University Katsina, Nigeria. \\ Muhammad Zubairu, PhD \\ Ahmadu Bello University Zaria, Nigeria
}

doi: 10.19044/esj.2016.v12n25p260 URL:http://dx.doi.org/10.19044/esj.2016.v12n25p260

\begin{abstract}
The aim of this paper is to explain the importance and implications of the use of Efficient Market Hypothesis (EMH) in emerging market with a view to see how portfolio assets are priced and the rationale behind it. The EMH describes a rational market where all relevant available information is reflected very quickly on prices. In an efficient market prices should react only to new unanticipated information, and since this is unpredictable, by definition, price changes must be unpredictable also. The EMH describes the case of an ideal stock market where actual prices fully reflect all relevant information. Consequently, the price and corresponding return fluctuations are not predictable and it's impossible for investors to make gains systematically. For many years, the EMH seemed to describe adequately the price behaviour in the world stock markets. Nevertheless, recent finding indicates otherwise. The research design of the paper is qualitative and content analysis is going to be use. The paper concludes that despite its shortcoming the EMH remains an open issue and it has help in deepening stock markets worldwide because of it acceptability. Therefore the paper recommends that more researchers should be encouraged to be conducted in emerging market of Africa especially that of Nigeria.
\end{abstract}

Keywords: Efficient Market Hypothesis, informational efficiency, random walk, Behavioural finance and share valuation

\section{Introduction}

The efficient market hypothesis $(\mathrm{EMH})$ is one of the widely discussed area and for that reason has received a lot of attention in the field of finance. Arguably, no other theory in economics or finance generates more passionate discussion between its challengers and proponents than EMH. For example, as noted by Harvard financial economist Michael Jensen, "there is no other 
proposition in economics which has more solid empirical evidence supporting it than the Efficient Market Hypothesis (Fortune, April 1995).The EMH is generally used in share asset valuation and stock market analysis.

EMH were firstly developed by Paul Samuelson (1965) and Fama (1970). Both researchers pointed out that the EMH assumes that share price adjust rapidly for any new information. consequently, the current prices fully reflect all available information's and should follow a random walk process, which means sequential stock price changes (returns) are independently and identically distributed (Ananzeh, 2014).

According to Investopedia (2015), the efficient market hypothesis as a whole theorizes that the market is generally efficient, and the theory is offered in three different versions: weak, semi-strong and strong. The basic efficient market hypothesis of investment posits that the market cannot be beaten because it incorporates all important determinative information into current share prices. Therefore, stocks trade at the fairest value, meaning that they can't be purchased undervalued or sold overvalued. Fama (1970) argued, the theory determines that the only opportunity investors have to gain higher returns on their investments is through purely speculative investments that pose substantial risk.

The efficient market hypothesis is associated with the idea of a "random walk," which is a term loosely used in the finance literature to characterize a price series where all subsequent price changes represent random departures from previous prices. The logic of the random walk idea is that if the flow of information is unimpeded and information is immediately reflected in stock prices, then tomorrow's price change will reflect only tomorrow's news and will be independent of the price changes today (Alexakis,1992). But news is by definition unpredictable, and, thus, resulting price changes must be unpredictable and random. As a result, Malkiel (2003), argued that, prices fully reflect all known information, and even uninformed investors buying a diversied portfolio at the tableau of prices given by the market will obtain a rate of return as generous as that achieved by the experts.

The efficient market hypothesis implies a special kind of efficiency which is informational efficiency in nature. The informational efficiency is the kind of efficiency when prices, under certain assumptions, reflect fully and very quickly, theoretically instantaneously, every piece of information concerning the traded securities (Alexakis, 1992). While according to Tijjani (2010), share prices follow a martingale model in which prices vary randomly around a constant mean.

Fama (1970), described an Efficient Capital Market as the market subject to the following theoretical conditions:

1. There are no transaction costs for the traded securities 
2. All available information is costless and available to all market participants.

3. All participants agree on the implication of current information for the current price.

The argument is that, the above conditions are sufficient but not necessary for market efficiency. For instance the market may be efficient, if a sufficient number of investors have ready access to available information. Also, disagreement among investors about the implication of given information does not in itself imply market inefficiency, unless there are investors who can consistently make better evaluations of available information that is implicit in market prices. The efficient market theory states that only factors not linked with future profitability, like investors psychology, should not affect stock prices (Alexakis, 1992b). But even this assertion according to William (2014) has being debunked by the behavioural sciences.

The rest of the paper is organized as follows; section two will treat literature review, section three comprises of detail analysis of what happened in the real world (empirical analysis of EMH on developed and emerging markets), while section four conclude and makes recommendation.

\section{literature review}

The literature review will dwell on the composition of efficient market hypothesis and other related theory on stock market as well as some related empirical studies conducted on EMH for both developed and emerging market of the world.

\section{Composition of Efficient Market Hypothesis}

Fama (1970) published a reassessment of efficient market hypotheses theory with an empirical base, and distributed market efficiency into three levels based on information: weak, semi-strong and strong form.

\section{Weak-Form EMH:}

Weak-form of efficient market hypotheses assumes that the current stock prices fully reflect all historical market information such as: (historical sequence of prices, trading volumes, and any market generated information). Weak EMH suggests that today's stock prices reflect all the data of past prices and that no form of technical analysis can be effectively utilized to aid investors in making trading decisions. Advocates for the weak form efficiency theory allow that if fundamental analysis is used, undervalued and overvalued stocks can be determined, and investors can research companies' financial statements to increase their chances of making higher-than-market-average profits. 


\section{Semi strong-form EMH:}

Semi-strong form of EMH assumes that the current stock prices reflect not only the historical information but also new publicly available information such as: dividend announcements, economic and political news. Therefore according to Investopedia (2014) the semi-strong form efficiency theory follows the belief that because all information that is public is used in the calculation of a stock's current price, investors cannot utilize either technical or fundamental analysis to gain higher returns in the market. Those who subscribe to this version of the theory believe that only information that is not readily available to the public can help investors boost their returns to a performance level above that of the general market.

\section{Strong EMH:}

The strong-form efficient market hypotheses assume that stock prices reflects all information from both public and private sources, so that no one investor can reap abnormal rate of return. The strong form version of the efficient market hypothesis states that all information - both the information available to the public and any information not publicly known - is completely accounted for in current stock prices, and there is no type of information that can give an investor an advantage on the market. Advocates for this degree of the theory suggest that investors cannot make returns on investments that exceed normal market returns, regardless of information retrieved or research conducted.

\section{Theoretical Framework of EMH}

The theory of the efficient markets has a long history and caused a debate between academics and practitioners for many years now. Some studies gave supportive evidence for the efficient market hypothesis and some others, among them the most recent, did not. Some researchers who have discovered price behaviour different from what the efficient market hypothesis implies and proposed alternative theories to explain these deviations. On the top of that debate Chaos theory says that price changes are the result of complex non linear dynamic models. At a first glance price changes may look like random, but if someone looks deep in them will be able to find structure because in Chaos theory structure and randomness are closely related.

In this section the researcher will give a picture of the history of the efficient market theory based on theoretical and empirical work in this area of research which is still considered as open.

\section{Fundamental and Technical Analysis}

Early works on capital markets by Williams, The theory of investment value (1938), and Graham \& Dodds Security analysis (1934), were built on 
the notion of "intrinsic" or "fundamental" value of securities which equals the discounted cash flow these securities generate; and the belief that actual prices fluctuate around fundamental values. According to the above idea the suggested strategy for someone is to buy when the price of a stock is below its intrinsic value and sell when it is above its intrinsic value in order to realize trading profits when the disparity is eliminated. Thus, fundamental analysts tried, and still do, to perform projections of securities future cash flows. This according to Tijjani (2010) involved analyzing factors like the demand for the product, possible future development of substitutes, the environment of the firm and the industry even the economy as a whole. In short, all information relevant to future profitability of the firms in question is considered. Apart from fundamental analysis investors also applied technical analysis by trying for example to identify specific graphical patterns in stock prices.

\section{Behavioural Finance Theory}

Behavioural finance is the study of the influence of psychology on the behaviour of financial practitioners and the subsequent effect on markets. Behavioural finance is of interest because it helps explain why and how markets might be inefficient. Behavioural finance takes issue with two crucial implications of the EMH: (1) that the majority of investors make rational decisions based on available information; and (2) that the market price is always right. Proponents of behavioural finance, or behaviourists, as they often are known, believe that numerous factors-irrational as well as rational-drive investor behaviour. In sharp contrast to efficient markets theorists, behaviourists believe that investors frequently make irrational decisions and that the market price is not always a fair estimate of the underlying fundamental value. Refuting Fama's crucial assertion that the market price is always right, behaviourists' - believe investor psychology can drive market prices and fundamental value very far apart (Williams, 2014).

The pricing anomalies that had been discovered (in the 1970s) might be considered at worst small departures from the fundamental truth of market efficiency, but if most of the volatility in the stock market was unexplained, it would call into question the basic underpinnings of the entire efficient markets theory (Shiller ,2003). In 1981, Shiller published an article in the American Economic Review in which he documented evidence of price movements much greater than an efficient market would allow. Four years later Richard Thaler and Werner de Bondt (1985) published a study that concluded that the stock market tends to overreact to a long series of bad news. This is evident in what happened in Nigeria stock exchange during the 2008 global meltdown, which affected the global economy, where the entire market nearly crashes as a result of bearish nature of the market owing to the consistent down spiral of the equity prices. 


\section{The Random Walk Model}

Based on a $1900 \mathrm{PhD}$ thesis of the French mathematician Luis Bachelier, in it appeared statistical evidence that stock price changes are unforecastable since they are a cumulated series of probabilistically independent shocks which are identically distributed. It was claimed that stock prices follow the random walk model.

According to Fama (1970) an efficient market is a market in which prices reflect all available information. In the stock market, the intrinsic value of a share is equivalently measured by the future discounted value of cash flows that will accrue to investors. If the stock market is efficient, share prices must reflect all available information which is relevant for the evaluation of a company's future performance, and therefore the market price of share must be equal to its intrinsic value. Any new information, which is expected to change a company's future profitability, must be immediately reflected in the share price because any delay in the diffusion of information to price would result in irrationality, as some subsets of available information could be exploited to forecast future profitability. Thus, in an efficient market, price changes must be a response only to new information. Since information arrives randomly, share prices must also fluctuate unpredictably.

\section{Empirical Evidences of EMH from the Emerging Market}

The empirical literatures on the weak form efficiency in emerging stock markets by different authors show conflicting result. some authors support while many others oppose the efficient market hypothesis. The weak form of EMH implies that current market prices of stocks are independent on their past prices. In other words, a market is efficient in the weak form if stock prices follow a random walk process. Therefore, tests of weak form efficiency are naturally based on an examination of the interrelationship between current and past stock prices (Fawson, 1996).

Data obtained for testing weak form of EMH in emerging stock markets include stock price indices and/or individual stock prices series. Specifically, stock price indices were used in studies of Sharma and Kennedy (1997), , Fawson et al. (1996), Dockery and Vergari (1997) Abeysekera (2001), Abraham et al. (2002), Lima and Tabak (2004) also Mikailu and Sanda (2007), Tijjani (2010), while individual stock prices are employed by Dickinson and Muragu (1994), Olowe (1999), Wheeler (2002). Especially, Barnes (1986), Seddighi and Nian (2004) employed both kinds of data for their tests in order to detect the weak form of market efficiency. Another aspect of data used for testing weak form efficiency hypothesis in emerging stock markets is frequency of time series (Tijjani, 2014). 
Empirical findings derived from the studies in emerging stock markets have been mixed. Indeed, some studies provide empirical results to reject the null hypothesis of weak form market efficient while the others show evidence to support the weak form of EMH. Regarding emerging European stock markets, for instance, the empirical evidence obtained from Wheeler et al. (2002) fails to support the weak form efficient hypothesis for the Warsaw Stock Exchange (Poland). On the other hand, Dockery and Vergari (1997) document that the Budapest Stock Exchange is efficient in the weak form. In addition, Karemera et al. (1999) shows empirical evidence to support the null hypothesis of weak form market efficiency for the stock market in Turkey. Surprisingly, in the perspective of Africa, Dickinson and Muragu (1994), Olowe (1999) and Mikailu \& Sanda (2007) find that the Nairobi and Nigerian stock exchanges respectively are efficient in the weak form.

Studies conducted by Tijjani (2010) on share valuation and stock market analysis in Nigeria stock exchange (NSE) indicate that a returns on the NSE appear to be volatile while few correlation are statistically significant which suggest that the weak- form of the EMH cannot be rejected for the NSE. According to Godwin (2010), the weak form hypothesis has been pointed out as dealing with whether or not security prices fully reflect historical price or return information. To carry out this investigation with the Nigerian stock market data, he employed the run test and the correlogram/partial autocorrelation function as alternate forms of the research instrument. His results of the three alternate tests revealed that the Nigerian stock market is efficient in the weak form and therefore follows a random walk process. He concluded that the opportunity of making excess returns in the market is ruled out. However, there are many conflicting studies on the issue of EMH on the Nigerian Stock Market

Dahel and Laabas (1999) reported that the Kuwait stock market strongly support the weak form of EMH, and reject the weak form of the EMH for Bahrain, Saudi Arabia and Oman.. Also, Abeysekera (2001) and Abraham (2002) their empirical finding reject the hypothesis of weak form efficiency for stock markets in Sri Lanka, Bahrain Kuwait,and Saudi Arabia.

Empirical study conducted by Gimba (2012), consist of daily and weekly price series of the market index (NSINDEX) and the five oldest stocks (FIRSTB, UBA, UNIONB, CADBURY and NESTLE) listed on the Nigerian stock exchange. The results obtained from the autocorrelation indicate that the null hypothesis of random walk is conclusively rejected for the market index and four out of five selected individual stocks, even in the case where the returns are corrected for thin trading. In addition, the runs test shows evidence to reject the null hypothesis of a random walk for both daily and weekly observed returns of the market index and all selected individual stocks (except weekly returns for UNIONB). However, when the corrected returns are used, 
the empirical results given by the tests fail to reject the null hypothesis for the daily returns of UNIONB and NESTLE and weekly returns for FIRSTB and NESTLE. The author concludes that the Nigerian stock market is inefficient in the weak form.

\section{Empirical Studies on EMH on Developed Market}

Studies conducted on more advanced and developed market tends to disprove the underlying assumptions of EMH in the weak form that shares prices are on predictable. According to Osborne (1959) the Efficient Market Hypothesis states that returns (the opening price subtracted from the closing price) of market indices in efficient markets behave like Brownian motion. In practice, this assumption is violated mostly by the periodic structure (day, week, quarter, and year) of agent behaviour.

Chordia (2008) applies regression and variance ratios to study shorthorizon returns on NYSE stocks; they found that decreasing the minimum tick size and periods of greater liquidity reduces predictability. Griffin (2010) use trading strategies over a wide range of emerging and developed markets and show that applying common tests without accounting for private and public informational efficiency aspects can give misleading results. McPherson and Palardy (2007) develop generalized spectral tests for testing of linear and nonlinear predictability and examine predictability of data from large markets.

Another method of disproving the weak EMH is to discover systematic empirical periodic deviations (anomalies). Rozeff and Kinney (1976) introduced a seasonal effect called the January effect: in the beginning of every year, small stocks returns tend to be higher than in any other month. As a result of tax-related moves, it has been shown that investors profit by buying stocks in December when they are sold at a lower price and then selling them again in January. Gibbons and Hess (1981) found the weekly Monday effect: stock prices tend to go down on Mondays and there is a negative average return because of weekend non-trading days.

\section{Conclusion and Recommendation}

The Efficient Market Hypothesis states that prices fully and very quickly reflect all available information so no one can earn excess profits based on that information. According to the EMH prices should react only to the unanticipated news, but since this news is unforecastable, by definition, price change must be unforecastable. Early empirical work supported the above hypothesis. Nevertheless, recent studies in stock price behaviour report several deviations from the implications of market efficiency. First, researchers report a number of calendar and non calendar anomalous findings which cannot be explained in the framework of the EMH. 
Second, it is argued that prices do not react only to information but there are other factors which influence stock prices like investors psychology according to behaviourist finance. Finally, chaos theory and its complexity recognise these non-rational factors but chaos theory is in line with the EMH that prices are unforecastable. Alexakis (1992) based his argument on this famous statement: after a century of debate the efficient market hypothesis is still an open issue and that there is much more to be said in the future because (I know one thing; that I know nothing) Socrates 500 B.C. Athens.

Based on the conclusion above the EMH is still a theory that need more exploring especially in the emerging market of Africa. And for that reason the following recommendations are made.

Establishing a stock exchange news service, which will be responsible for early, equal and wide dissemination of price sensitive news such as financial results and other information that are material to investors' decision. This will ensure that participants and investors have equal access to high quality and reliable information and it will reduced drastically the information insiders get from other investing public which leads to insider abuse as we have seen in 2009 capital market crisis in Nigeria.

The emerging market of Africa needs to urgently improve on the automation of their listing as well as demutualizing their shares especially in Nigeria through the Central Security Clearing System (CSCS), so that investors can sell and buy shares through the internet without much hassle.

Instituting efficient and effective corporate governance at firm level will go a long way in reducing corporate abuses as regards information released to the investing public and also it will go a long way in curtailing speculative tendencies of insiders with privilege information.

\section{References:}

Abeysekera,P., S. "' Efficient Markets Hypothesis and the Emerging Capital market in Sri Lanka: Evidence from the Colombo Stock Echange - A Note, Journal of $\quad$ Business Finance and Accounting 28 (1):249-261.2001 Abraham F., j. ' 'Testing the Random Walk Behaviour and Efficiency of the Gulf stock markets. The Financial Review 37:469-480. 2002

Alam, M. I, and Tanweer, H, and P-R. Kadapakkam,' An Application of Variance-Ratio Test to Five Asian Stock Markets. Review of Pacific Basin Financial Market and Policie 2 (3):301-315. 1999.

Alexakis,C. ' An empirical investigation of the efficient market hypothesis: The Case study of the Athens stock exchange. A PhD dissertation at the department of Economics and related studies, University of York Herligton, England. 1992.

Paul,B. 'Thin Trading and Stock Market Efficiency: the Case of the Kuala 
Lumpur Stock Exchange'’. Journal of Business Finance and Accounting 13 (4):609617. 1986

Bashir, J. 'Testing Efficient Market Hypothesis; New evidence'”. Available online At http://www.journals.co.za/ej/ejour_finj.html,2014

Buguk, C. and B. W Brorsen, B.' 'Testing Weak-Form Efficiency: Evidence from the Instabul Stock Exchange". International Review of Financial Analysis 12, pp. 5792002

Kuo-Ping and Kuo-Shiuan T. A variance Ratio Test of the Random Walk Hypothesis for Taiwan's Stock Market. Applied Financial Economics 10:525532.2000

Cheung, C, Kwong- and J.A.Coutts, J.A (2001). 'a Note on Weak Form Market Efficiency in Security Prices: Evidence from the Hong Kong Stock Exchange;;. Applied Economics Letters 8: 407-410

J.P. Dickinson, and K. Muragu, 'Market Efficiency in Developing Countries: A Case study of the Nairobi Stock Exchange'. Journal of Business Finance and Accounting, 21 133- 150. 1994

Dockery,E and F Vergari '’Testing the Random Walk Hypothesis: Evidence for the Budapest Stock Exchange. Applied Economics letters 4:627-629.Fama E.F. (1970). Efficient Capital Market: A review of Theory and Empirical Work. Journal of Finance 25(2):382-417 May, 1997

Fawson,C T., Glover W. Fang W., and T. Chang "The Weak-Form Efficiency of the Taiwan Share Market'. Applied Economics Letters 3:663-667. 1996

Godwin, C. 'Stock market prices and the random walk hypothesis: Further evidence from Nigeria". Available online at http://www.academicjournals.org/JEIF ISSN 2006-20109812@2010 Academic Journals.

Grieb, T and M.G. Reyes, M.G 'on Random Walk Tests for Latin American Equity Indexes and Individual Firms. Journal of Financial Research 22 (4):371-383.1999

Groenewold, N, Sam, T and Wu, Y 'The Efficiency of the Chinese Stock Market and the Role of the Banks." Journal of Asian Economics 14: 593-609. 2005

Huber, P" Stock Market Returns in Thin markets: Evidence from the Vienna Stock Exchange. Applied Financial Economics 7: 493-498.1997

Karemera,D, Ojah, K and Cole, J. A ' Random Walks and Market Efficiency Tests: evidence from Emerging Equity Markets'. Review of Quantitative Finance and Accounting 13:171-188 2009.

Lima, E, J, and Tabak, B, M 'Tests of the Random Walk Hypothesis for Equity Markets: Evidence from China, Hong Kong and Singapore'. Applied Economics Letters 11: 255-258. 2004. 
Liu, Y. U and He, J. A variance-Ratio Test of Random Walks in Foreign Exchange Rates'. The Journal of Finance 46 (2), pp. 773-785. 1991

Lo, A. W. \& MacKinlay A. C. Stock Market Prices Do not Follow Random Walk: Evidence from a Simple Specification Test. The Review of Financial Studies 1 (1):41-66. 1988

Mikailu, A.\& Sanda U. A. Are stock returns randomly distributed? New evidence from the Nigerian stock exchange. Journal of Accounting and Finance Vol.2. 2007

Miller,M, H, Jayaram, M and R.E Whaley " Mean Reversion of Standard \& Poor's 500 index Basis Changes: Arbitrage-Induced or Statistical Illusion? $\begin{array}{lll}\text { 'Journal of Finance } 49 & \text { 2):479-513. } 1994\end{array}$

Mookerjee, R. \& Yu O., (1999). An Empirical Analysis of the Equity Markets in China. Review of Financial Economics 8: 41-60. 1994

Sanda,A, U. " Test for Random Walk Hypothesis on the Nigerian Stock Market" Journal Of Accounting and Finance V11, 2009.

Seddighi,H,R, and W. Nian 'The Chinese Stock Exchange Market: Operations and Efficiency. Applied Financial Economics 14: 785-797. 2004.

Sharma,J, R, and Kennedy, R, E. ' 'A comparative Analysis of Stock Price Behaviour on the Bombay, London, and New York Stock Exchanges. Journal of Financial Quantitative Analysis. 391-413. 1997

Urrutia, J, L," Test of Random Walk and Market Efficiency for Latin American Emerging equity Markets. The Journal of Financial Research 18 (3): 299-309. 1995

Wheeler, F, P, Bill K. Tadeusz, F, and Steve, R,L. " The Efficiency of the Warsaw Stock Exchange: the First few Years 1991-1996. The Poznan University of Economics Review (2):2 37-56. 2002

Williams, S,T. 'The causal relationship between stock price and interest rate. A Research project for the award of post-graduate diploma in Acturial science, 2014 University of Kenya, Nairobi.

Tijjani, B. Share valuation and stock market analysis in emerging markets: A case of Nigeria.Adamu joji publishers, Gwarzo road, opposite FCE Kano-Nigeria. 2010

Wong, K. A., \& Kwong, K. S. (1984). The Behaviour of Hong Kong Stock Prices. Applied Economics 16:905-917.1984 